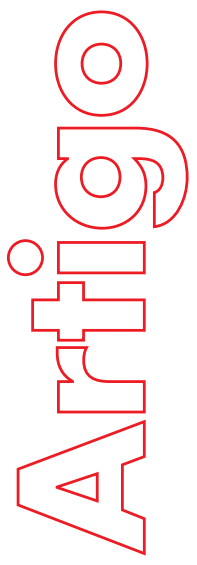

\title{
O REORDENAMENTO NO ESPAÇO RURAL
}

\author{
Marinês da Conceição Walkowski \\ Mirtz Orige Oliveira \\ Vinicius Boneli Vieira \\ Carlos Loch
}

p. $01-24$

Como citar este artigo:

WALKOWSKI, M. C., Mirtz Orige Oliveira, Vinicius Boneli Vieira, Carlos Loch. O REORDENAMENTO NO ESPAÇO RURAL. Revista

revista

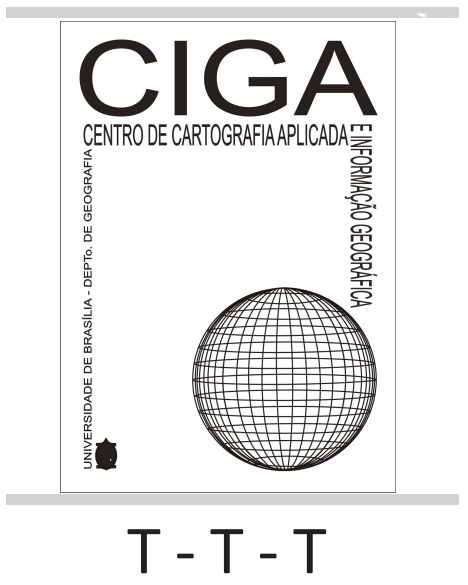

Revista Eletrônica: Tempo - Técnica - Território, V.5, N.2 (2014), 1:24 ISSN: $2177-4366$ DOI: https:// doi.org/10.26512/ ciga.v5i2.15393
Eletrônica: Tempo - Técnica - Território, v.5, n.1 (2014), p. 01:24

ISSN: 2177-4366. DOI: https://doi.org/10.26512/ciga.v5i2.15393

Disponível em:http://periodicos.unb.br/index.php/ciga/

Este obra está licenciado com uma Licença Crea tive Commons Atribuição-NãoComer cial 4.0 Inter nacional. 


\title{
O REORDENAMENTO NO ESPAÇO RURAL
}

\author{
Marinês da Conceição Walkowski \\ Bacharel em Turismo, Doutorado em Arquitetura e Urbanismo pela Universidade de \\ Santa Catarina, Brasil (2013). \\ E-mail: \\ marinesw@yahoo.com.br \\ Mirtz Orige Oliveira \\ Arquiteta, Doutoranda em Engenharia Civil pela Universidade de Santa Catarina, Brasil \\ (2013). \\ E-mail: \\ Mirtz.orige@posgrad.ufsc.br \\ Vinicius Boneli Vieira \\ Bacharel em Turismo, Mestre em Geografia pela Universidade Federal do Paraná, \\ Brasil \\ E-mail: viniciusbonelli@gmail.com \\ Carlos Loch \\ Professor, Dr. Departamento de Engenharia Civil pela Universidade de Santa Catarina, \\ Brasil. \\ E-mail: \\ loch@ecv.ufsc.br
}

\begin{abstract}
RESUMO: O espaço rural brasileiro apresenta potencial para diferentes atividades sendo fundamental o reordenamento no espaço rural visando o rearranjo das propriedades existentes em uma área de forma a otimizar o uso do solo observando aspectos ecológicos, sociais, econômicos e paisagísticos. O objetivo deste trabalho é comparar três projetos de reordenamento no espaço rural desenvolvidos na região serrana catarinense entre 2001 e 2009. Atualmente a área da região serrana catarinense é compreendida por um conjunto de onze municípios os quais sofreram métodos diferentes de reordenamento. A metodologia utilizada nesse trabalho foi à pesquisa bibliográfica, exploratória e descritiva por meio de entrevistas em campo. Concluiu-se que para que haja viabilidade nos projetos de reordenamento no espaço rural é preciso levar em consideração os fatores econômicos, ecológicos e sociais. Muitos projetos de reordenamento foram elaborados sem levar em consideração os preceitos básicos, como, por exemplo, a melhoria na qualidade de vida da população e a diminuição da ocupação desordenada. Também foram observadas, algumas dificuldades com a falta de fiscalização dos órgãos estaduais, a falta de profissionais habilitados para a elaboração e execução dos projetos e o baixo nível de escolaridade de algumas classes sociais, inibindo o entendimento e a participação no processo.
\end{abstract}

Palavras chave: Espaço Rural; Reordenamento; Cadastro Técnico Multifinalitário; Serra Catarinense.

ABSTRACT: The Brazilian rural area has potential for different activities is fundamental reordering in rural targeting the rearrangement of existing properties in an area in order to optimize the use of land observing ecological, social, and economic landscape. The objective of this work is to compare three redevelopment projects in rural areas developed in the highlands of Santa Catarina between 2001 and 2009. Currently the area of the mountain region of Santa Catarina is comprised of a set of eleven municipalities which experienced different methods of reordering. The methodology used in this study 
was the literature research, exploratory and descriptive in interviews in the field. It was concluded that for there to be viable in the redevelopment projects in rural areas it is necessary to take into account the economic, ecological and social. Many redevelopment projects were prepared without taking into account the basic principles, such as, improvement in quality of life and reduction of sprawl. Were observed, some difficulties with the lack of supervision of state agencies, the lack of qualified professionals for the design and implementation of projects and the low educational level of some social classes, inhibiting understanding and participation in the process.

Keywords: Rural; Reorganization; Multipurpose Technical Cadastre; Sierra Santa Catarina.

RESUMEN: La zona rural de Brasil tiene potencial para las diferentes actividades se reordenamiento fundamental en la orientación de las zonas rurales de la reordenación de las propiedades existentes en una zona con el fin de optimizar el uso de la tierra observando paisaje ecológico, social y económico. El objetivo de este trabajo es comparar tres proyectos de reconstrucción en las zonas rurales desarrolladas en la sierra de Santa Catarina, entre 2001 y 2009. Actualmente, el área de la región de la montaña de Santa Catarina se compone de un conjunto de once municipios que experimentaron diferentes métodos de reordenamiento. La metodología utilizada en este estudio fue la investigación bibliográfica, exploratoria y descriptiva en las entrevistas sobre el terreno. Se concluyó que para que haya viable en proyectos de reconstrucción en las zonas rurales, es necesario tener en cuenta los aspectos económicos, ecológicos y sociales. Muchos se prepararon proyectos de nuevo desarrollo, sin tener en cuenta los principios básicos, tales como, la mejora en la calidad de vida y la reducción de la dispersión. Se observaron, algunas dificultades con la falta de supervisión de las agencias estatales, la falta de profesionales cualificados para el diseño y ejecución de proyectos y el bajo nivel educativo de algunas clases sociales, la inhibición de la comprensión y la participación en el proceso.

Palabras clave: Rural; Reorganización; Multipurpose Catastro Técnico, Sierra de Santa Catarina.

\section{INTRODUÇÃO}

Segundo o Dicionário Aurélio da Língua Portuguesa, o verbo reordenar significa “tornar a pôr em ordem; tornar a arranjar; dispor”. Assim, o reordenamento no espaço rural pode ser definido como o rearranjo das propriedades existentes em uma área de forma a otimizar o uso do solo observando aspectos ecológicos, sociais, econômicos e paisagísticos.

O delineamento das características físicas e legais das propriedades privadas vem sendo discutido em muitos lugares do mundo. O processo de reordenamento de espaços rurais e urbanos é desenvolvido na Alemanha, Japão, Holanda, China e EUA (HONG; NEEDHAM, 2007). Também no Brasil existem experiências neste sentido.

Em muitos lugares o solo não é usado de forma ótima. Isto ocorre, muitas vezes, porque a propriedade é entendida como absoluta, ou seja, porque os proprietários acreditam ter direito de utilizá-la sem se preocupar com aspectos públicos e coletivos. Esta atitude pode levar a diversas conseqüências negativas para a sociedade, como subutilizações dos espaços produtivos desrespeitam a legislação ambiental e 
crescimento desordenado. O uso da propriedade privada deve ser mediado por direitos do Estado, como leis ambientais; e direitos de vizinhança, não apenas nas áreas urbanas, mas também nas áreas rurais. No entanto, quando a situação negativa já está estabelecida ainda existe a possibilidade de reordenar.

De forma geral, é possível apontar motivos para reordenar espaços rurais:

a) Possibilitar o acesso a terra para todos;

b) Aperfeiçoar a infraestrutura para população e para produção agrícola;

c) Evitar o crescimento urbano desordenado sobre as áreas rurais;

d) Melhorar a produção primária;

e) Organizar malha de transportes para escoamento de produção agrícola.

Segundo Neumann (2003), são objetivos de processos de reordenamento: promover as condições de desenvolver uma agricultura mais eficiente e aumentar as possibilidades de florestamentos; promover as condições para a eficiência agrícola e para a proteção e a gestão de espaços naturais; promover o aumento da produção e a melhoria nas condições de trabalho, no reflorestamento, na gestão e no uso do solo e planejar o layout e as estruturas das áreas rurais de acordo com as diversas funções.

Para que os objetivos de um processo de reordenamento em espaços rurais sejam atingidos é necessário considerar alguns critérios de viabilidade. Um destes critérios é a viabilidade econômica. É importante observar as atividades econômicas desenvolvidas na região a ser reordenada e considerar as características necessárias para a continuidade e melhoria destas atividades. Neste sentido, se deve avaliar a relação entre as unidades reais e ideais de produção agrícola e a influência da geometria nesta produção.

Outro critério a ser considerado é a viabilidade ecológica. A atividade agrícola é essencial para atender as necessidades da vida humana. No entanto, esta atividade está baseada na utilização de recursos naturais renováveis e não-renováveis. Sem entrar no mérito da discussão sobre a utilização de recursos não-renováveis, qualquer projeto de reordenamento deve considerar a importância das áreas legalmente protegidas no meio rural.

Por fim, ainda é necessário observar o critério de viabilidade social. É importante considerar diversos aspectos para garantir a qualidade de vida da população que ocupa a área a ser reordenada. Entre estes aspectos é possível citar a paisagem, os usos coletivos e aspectos culturais. 
No contexto desta discussão, o objetivo deste trabalho é comparar três projetos de reordenamento no espaço rural desenvolvidos na região serrana catarinense entre 2001 e 2009.

\section{A POSSE DA TERRA NO BRASIL}

Em Portugal, prevalecia a filosofia de estímulo a produção primária. Desde o século XIV, existia o dispositivo legal que permitia ao governo português desapropriar terras não produtivas. O Brasil se tornou uma colônia de Portugal a partir de 1500. A primeira tentativa de ordenamento do novo território foi a implantação do sistema de Capitanias Hereditárias. Este sistema foi adotado em muitas colônias portuguesas e estava baseado no princípio privatístico da propriedade. (LOCH; ERBA, 2007).

Estas capitanias eram subdivididas em parcelas denominadas Sesmarias com seu respectivo título, a Carta de Sesmaria. Estas parcelas eram doadas para candidatos com a intenção de povoar o solo, dotados de capacidades de gerenciamento e negociação, delegando poderes e privilégios conforme estatuto da Capitania (MEDEIROS, 2002). Foi a partir das Sesmarias que se ramificou a propriedade imobiliária brasileira (LOCH; ERBA, 2007). A demarcação das sesmarias foi problema que perdurou por séculos. Entre as principais dificuldades é possível citar as despesas com funcionários nomeados para a função de demarcação, bem como, dificuldades relacionadas com o desconhecimento do território colonial. Mesmo assim, continuaram a serem emitidas as cartas de sesmarias, baseadas em informações imprecisas. Isto levou a múltiplos problemas, como áreas com diferentes sesmeiros nomeados, ocupação de terras públicas e surgimento de latifúndios (MARIGHELA, 1980).

A idéia de estimular a produção primária e a ocupação do solo em território brasileiro através da concessão de Sesmarias persistiu até 1822. Neste ano, uma resolução (n ${ }^{\text {o. }} 76$ de 17 de julho de 1822) suspendeu a concessão. Segundo Loch e Erba (2007), a partir daí a posse e a ocupação de terras se proliferam. Mesmo com a Constituição Imperial de 1824 esta situação não se resolveu. Diante desta situação o Governo Imperial Brasileiro promulgou em 1850 a Lei de Terras ( ${ }^{0 .} 601$ de 18 de setembro de 1850). Esta lei iniciou a construção de um sistema de organização administrativa das terras brasileiras, a partir da discriminação entre terras públicas e privadas. Dispunha sobre a compra e venda de terras devolutas do Estado e sobre a revalidação da posse da terra por título de Sesmarias, entre outros temas (LOCH; ERBA, 2007). 
A Lei de Terras foi regulamentada em 1854 pelo Decreto Imperial 1318 de 30 de novembro. Com este decreto foi criada a Repartição Geral de Terras Públicas que tinha por atribuições: medir as terras públicas; legitimar as terras de particulares e a venda de terras públicas; instituir o regime de fiscalização de terras devolutas; e criar o registro paroquial. Além disso, esta lei instituiu o Registro de Terras Possuídas que obrigava todos os proprietários com títulos de propriedade ou posse a registrar suas terras. No entanto, não foi exigida a planta de medição no momento do registro. Em 1890, o Decreto 451B exigiu o registro de qualquer ato que modificasse a área em questão. Este decreto dispunha ainda sobre a planta e a avaliação dos imóveis. Estabeleceu a necessidade de fixação de marcos referenciais estáveis que permitissem a incorporação da planta da propriedade com a Carta Geral Cadastral entre outros detalhes importantes. A partir da constituição republicana de 1891, as terras públicas foram delegadas aos estados federados. Assim, os estados passaram a ser responsáveis por legislar sobre assuntos relacionados as terras de domínio público. Esta situação foi reafirmada pela constituição republicana de 1931 (LOCH; ERBA, 2007).

Poucas menções legais haviam sido feitas no que se refere aos mecanismos de reordenamento agrário no Brasil até a lei $\mathrm{n}^{\text {0. }} 4504$ de 1964, chamada de Estatuto da Terra. Esta lei regulamentou diversos aspectos relacionados com a Reforma Agrária, como os direitos e obrigações relacionados aos imóveis rurais. Além disso, assegura a oportunidade de acesso a terra a todos, condicionada a sua função social, como parte da política agrícola nacional. Prevê a necessidade de zoneamentos e cadastros envolvendo as terras públicas, particulares, de posseiros e as devolutas. Também foi esta legislação que criou o Cadastro de Imóveis Rurais do Brasil. Este estatuto propôs, pela primeira vez na legislação brasileira, o uso do crédito fundiário como forma de o acesso à terra através da compra e venda de propriedades rurais com financiamentos públicos de longo prazo e subsidiados.

Em 1969, o decreto-lei $n^{\text {o. }}$ 554, regulamentado pela lei $n^{0 .} 5868$ de 1972 e pelo decreto $\mathrm{n}^{\text {o. }} 72106$ de 1973, trataram da desapropriação de imóveis rurais para reforma agrária visando cumprir a função social da propriedade. Em 1970 foi criado o Instituto Nacional de Colonização e Reforma Agrária (INCRA) e o Sistema de Cadastro Rural Nacional que incluía o Cadastro de Imóveis Rurais, Cadastro de Proprietários e Detentores de imóveis Rurais, Cadastro de Arrendatários e Parceiros Rurais, Cadastro de Terras Públicas (LOCH; ERBA, 2007). 
Na década de 1980, o reordenamento em espaços rurais passou a ser discutido através da elaboração do Plano Nacional de Reforma Agrária, decreto n ${ }^{\text {o. }} 91766$ de 1985 (LOCH; ERBA, 2007). A proposta deste plano era promover a justiça social, aumentar a produção, aumentar a oferta de alimentos, criarem novos empregos e diminuir o êxodo rural assentando milhões de famílias em 15 anos (GRAZIANO DA SILVA, 1985).

Em 1988, foi promulgada nova constituição federal. Em seu capítulo chamado Ordem Econômica e Social, artigo 184, ficou garantida a função social da terra, através da desapropriação dos imóveis rurais improdutivos, causadores de degradação ambiental e que não respeitam os direitos dos trabalhadores (LEITE; ÁVILA, 2007). A desapropriação garante o direito do ex-proprietário receber indenização em Títulos da Dívida Agrária (TDA), recebendo parcelas anuais de acordo com o valor da terra num prazo que varia entre cinco e 20 anos de acordo com o tamanho da área. Este processo de desapropriações ficou conhecido como reforma agrária redistributiva. No entanto, não ficaram definidos os critérios para a determinação de imóveis improdutivos, gerando polêmicas e possibilidade de recursos judiciais sobre as desapropriações (PEREIRA, 2009).

Nesta época, o Movimento dos Trabalhadores Sem-Terra (MST) buscou maior inserção no cenário político nacional e internacional, com o aumento do número de acampamentos e invasões realizados no Brasil (PEREIRA, 2009). O objetivo destas ações estava relacionado com o cumprimento da legislação brasileira sobre a reforma agrária.

A partir da década de 1990, o processo de descentralização políticoadministrativa federal reforçou a defesa de reordenamento dos espaços rurais brasileiros a partir da adesão voluntária a programas de crédito regulados pelo Estado como alternativas ao mecanismo de desapropriações (MEDEIROS, 2002). São exemplos deste tipo de iniciativa a institucionalização das bolsas de arrendamento e parceria, e a regulamentação da compra de terras.

Influenciado pelo crescente número de invasões de propriedades e manifestações populares favoráveis a reforma agrária, foram empreendidas algumas ações experimentais de reordenamento através de programas de crédito. Uma destas ações ocorreu em 1997 no estado do Ceará e foi fomentada pelo Banco Mundial, o projetopiloto São José (PEREIRA, 2004). A partir desta experiência foi criado o programa de caráter temporário chamado Cédula da Terra. Este programa abrangeu cinco estados do 
Brasil, Maranhão, Pernambuco, Bahia, Minas Gerais e Ceará (BRANDÃO, 2000; PEREIRA, 2004).

A Lei Complementar no 93, de quatro fevereiro de 1998, criou o Fundo de Terras e da Reforma Agrária, também chamado de Banco da Terra em caráter permanente. Este fundo visava a aquisição de terras por agricultores familiares com acesso precário a terra. A gestão deste fundo era realizada por um Conselho Curador formado por sete Ministros de Estado, pelo presidente do Banco Nacional de Desenvolvimento Econômico e Social (BNDES), pelo presidente do INCRA e por dois representantes dos trabalhadores rurais (PEREIRA, 2004; CAMARGO, 2003).

Mais recentemente, a lei $\mathrm{n}^{\text {o. }} 10267$ de 2001 trataram da implantação do Cadastro Nacional de Imóveis Rurais associado ao georreferenciamento das propriedades. Esta lei foi um marco para integração efetiva entre cadastro e registro de imóveis (LOCH; ERBA, 2007). A exigência de produtos cartográficos para compor o cadastro é extremamente importante para criar a base para políticas governamentais de reordenamento no espaço rural. Segundo Loch e Erba (2007), um dos principais problemas com o cadastro de propriedades no Brasil está na falta de ligação entre os registros de imóveis e os documentos cartográficos produzidos pelos profissionais. Assim, não é possível afirmar sobre a correlação entre a realidade do campo (a posse efetiva) e o direito adquirido (título de propriedade). Dessa forma, é difícil a intervenção na forma de reordenamento porque existem poucos dados confiáveis sobre a situação real das áreas rurais brasileiras.

Em 2003, foram criadas novas instituições para tratar das questões relacionadas ao reordenamento de espaços rurais, a Secretaria Nacional de Reordenamento Agrário (SNRA) e o Departamento de Crédito Fundiário (DCF), ambos vinculados ao Ministério do Desenvolvimento Agrário (MDA) (PEREIRA, 2009). Estas duas instituições governamentais visavam possibilitar a existência de duas (2) modalidades de reordenamento em espaços rurais no Brasil: a reforma agrária redistributiva e os programas de crédito fundiário. Para tanto, lançaram o II Plano Nacional de Reforma Agrária (PNRA). A inovação deste plano estava na inclusão de agricultores familiares, comunidades rurais tradicionais, as populações ribeirinhas, atingidos por barragens e outras obras de grande infraestrutura, ocupantes não índios das áreas indígenas, mulheres trabalhadoras rurais e juventude rural e outros grupos que habitam municípios rurais, mas não se dedicam às atividades agrícolas, como público para projetos de reordenamento em espaços rurais. 
Mesmo com estas iniciativas de reordenamento, os resultados do censo agropecuário brasileiro de 2006 mostraram o alto grau de desigualdade na distribuição da posse da terra no Brasil (IBGE, 2006). Segundo este estudo existe mais de 4,9 milhões de estabelecimentos agropecuários com área declarada que ocupam 330 milhões de hectares. A área média destes estabelecimentos é de 67,1 hectares. Os estabelecimentos com menos de 10 hectares representaram 50,3 \% do total e ocuparam 2,4\% da área total. Já os estabelecimentos com mais de 1.000 hectares representaram menos de $1 \%$ do total e ocuparam $44,4 \%$ da área.

Ainda neste estudo, o Instituto Brasileiro de Geografia e Estatística (IBGE) definiu quatro categorias relacionadas à condição de posse da terra: proprietário, arrendatário, parceiro e ocupante. Observando a evolução temporal das características da propriedade rural brasileira é possível perceber o crescimento da quantidade de proprietários que correspondiam a 64,1\% dos estabelecimentos em 1975, 74,5\% em 1995/96 e 80,2\% em 2006. Entre os censos agropecuários de 1995/96 e 2006 a área média dos estabelecimentos rurais da categoria de proprietários caiu de 92,0 ha para 77,8 ha. Já a área média dos estabelecimentos das categorias arrendatário, parceiro e ocupante aumentou.

Desde o Império, a legislação territorial brasileira teve como objetivo a demarcação e registro de imóveis componentes do patrimônio público e privado. Apesar da necessidade de reordenar o território brasileiro ser uma questão percebida e discutida no Brasil há bastante tempo, somente a partir da década de 1960 este tema passou a compor uma legislação específica. A partir de então, foram se desenvolvendo alguns mecanismos de reordenamento em espaços rurais no Brasil. Atualmente, os projetos de reordenamento estão relacionados a reforma agrária, a construção de obras de engenharia ou a utilização de instrumentos como o crédito fundiário previstos em políticas públicas. O reordenamento relacionado a reforma agrária é redistributivo, ou seja, propriedades consideradas improdutivas são desapropriadas e suas áreas parceladas entre famílias de agricultores. O reordenamento relacionado a grandes obras ocorre a partir de negociações entre empreendedores e populações atingidas. Já o reordenamento a partir de programas de crédito fundiário possibilita a aquisição de terras por agricultores através de financiamentos governamentais de longo prazo.

O ordenamento territorial brasileiro apresenta diversidade de leis sobre o tema. Mas, as ações práticas ainda não foram capazes de resolver as situações negativas 
existentes. Uma das razões para esta realidade pode estar relacionada com a baixa intervenção estatal no ordenamento territorial.

\section{SANTA CATARINA E A POSSE DA TERRA}

A ocupação do território catarinense está relacionada às sucessivas levas migratórias que contribuíram para a colonização do Brasil. Até o século XVIII o ocupação do território catarinense era quase exclusivamente indígena. Apenas as regiões litorâneas eram ocupadas por pequenas vilas com europeus e seus descendentes miscigenados às populações indígenas locais.

O território permite reconhecer os processos sociais, principalmente no que diz respeito às matrizes étnicas mais expressivas da população e às expropriações dos espaços. Assim, o território carrega as marcas do passado, a dinâmica atual e as linhas de força que mostram o que pode acontecer no espaço futuramente (FERREIRA; ANJOS, 2012).

Ao longo do século XIX, as elites políticas e intelectuais brasileiras visualizaram uma maneira de impulsionar o país à “estágios mais avançados” tanto social quanto economicamente: a imigração. Através da vinda de imigrantes seria substituído, paulatinamente, o trabalho escravo e, pela miscigenação, poderia - se branquear a população, surgindo daí, um tipo genuinamente brasileiro. O imigrante europeu seria o mais adequado a estes objetivos (SEYFERTH, 2000). O binômio imigração-colonização foi bastante forte durante o Império e segue na República. As elites políticas e intelectuais queriam para o Brasil uma imigração preferencial de lavradores brancos europeus que pudessem implantar no país uma nova forma de produção agrícola baseada na pequena propriedade (SEYFERTH, 2000).

Neste período começaram a chegar ao Brasil, novas levas de imigrantes vindos, principalmente, das regiões da atual Alemanha e Itália. Muitos destes imigrantes foram trazidos a Santa Catarina onde foram estabelecidos nos principais vales dos rios da planície litorânea. A demarcação dos terrenos ocorreu no sistema de linhas, que seguiam para dentro dos vales dos rios e riachos. De forma geral, é possível afirmar que a partir deste sistema de colonização se desenvolveu predominantemente nos espaços rurais catarinenses a pequena propriedade caracterizada pelo trabalho familiar. 
A partir deste processo migratório Santa Catarina se tornou um estado multiétnico com diferentes realidades agrícolas e fundiárias. Muitos destes descendentes de imigrantes conseguiram a propriedade das terras através da concessão de títulos de terra. Mas, muitos outros agricultores permaneceram em situações informais como arrendatários, posseiros ou ocupantes de terras.

As primeiras ações relacionadas ao ordenamento do território de Santa Catarina foram realizadas no século XX. O Decreto Estadual n ${ }^{\text {o. }} 82$ de 1931 e o Decreto $n^{\text {o. }} 46$ de 1934 criaram e regulamentaram o Cadastro Parcelário Territorial para o registro dos proprietários e o cadastro das parcelas em propriedade em Santa Catarina (LOCH; ERBA, 2007).

Na década de 1970, novas estratégias de ações visando o reordenamento no espaço rural passaram a ser discutidas no governo estadual. A partir destas discussões, foi criado o Fundo de Terras de Santa Catarina. Este fundo foi criado pela lei $\mathrm{n}^{\circ} 6.288$ de 31 de outubro de 1983 e regulamentado através do decreto $\mathrm{n}^{0} 20.842$ de 16 de dezembro de 1983. Seus objetivos eram garantir acesso a terra, através da compra dos terrenos por posseiros, arrendatários, meeiros, filhos de pequenos agricultores, pescadores artesanais, associações ou cooperativas de representação destas categorias (CAZELLA, 1995; CAMARGO, 2003; CONDÉ, 2006). A utilização deste fundo levou ao cumprimento de 59,42\% dos contratos em 20 anos. Outros 14,56\% dos contratos foram abandonados e 19,15\% foram transferidos ou estão em execução judicial. Quanto ao perfil do público beneficiário, 82\% eram arrendatários, 11,62\% eram filhos de pequenos agricultores e 6,10\% eram empregados rurais. Através deste fundo $73 \%$ das áreas adquiridas foram incorporadas aos processos produtivos, correspondendo a 2,7\% do total da área produtiva de Santa Catarina.

Em 17 de junho de 1992, através da lei agrícola nº 8.676 o Fundo de Terras foi incluído como um instrumento de política agrária catarinense. As bases deste fundo influenciaram a criação do Banco da Terra. Nesta mesma década passou a ser implantado no estado o Programa Nacional de Crédito Fundiário (PNCF). Até julho de 2009 foram atendidas por este programa 5.338 famílias (PEREIRA, 2009).

Outras áreas rurais em Santa Catarina foram reordenadas devido a obras de engenharia, principalmente usinas hidrelétricas. Também os movimentos sociais atuantes no estado conseguiram pressionar o governo e assentar famílias em diferentes regiões do estado, principalmente na serra e planalto catarinenses (BOEIRA, 2006; MDA, 2009). 
Santa Catarina apresenta alta incidência de unidades agrícolas gerenciadas por agricultores familiares e possui uma fronteira agrícola fechada, com poucas áreas passíveis de desapropriação por improdutividade, mas com diversas áreas passíveis de compra e venda (PEREIRA, 2009). No que se refere ao reordenamento em espaços rurais, é possível perceber que Santa Catarina apresenta uma situação semelhante ao restante do país. É possível afirmar que existe pouca intervenção estatal no sentido de reordenar áreas rurais para atender a sua função social, aumentar a produção agrícola, melhorar a infraestrutura das áreas rurais ou evitar o crescimento urbano desordenado.

\subsection{A região serrana de Santa Catarina: experiências de reordenamento territorial}

A região serrana catarinense apresenta clima da região é Cfb, segundo Köeppen, ou seja, clima temperado constantemente úmido, sem estação seca, com verão fresco. A temperatura média anual varia de 13,8 a $15,8^{\circ} \mathrm{C}$, com máximas entre 19,4 a $22,3^{\circ} \mathrm{C}$, e a mínimas entre de 9,2 a $10,8^{\circ} \mathrm{C}$. A precipitação pluviométrica total anual 1.360 a 1.600 mm, com o total anual de dias de chuva entre 123 e 140 dias. A insolação total anual pode variar de 1.824 a 2.083 horas. A vegetação primária predominante na região eram os campos com capões, florestas ciliares e bosques de pinheiros, com predominância de ervas (Gramíneas, Ciperáceas, Leguminosas e Compostas). A vegetação atual é composta de campos intercalados por áreas de culturas anuais e poucos remanescentes florestais (EPAGRI, 1999).

A classe de aptidão agrícola predominante é a três (3), com 43,5\% da área total. Isto representa aptidão com restrições para culturas anuais, aptidão regular para fruticultura e boa aptidão para pastagem e reflorestamento. As maiores limitações para a agricultura são a pedregosidade e a fertilidade. A produção agrícola da região apresenta predominância da pecuária, sob o sistema extensivo, de gêneros básicos, como milho e feijão. Outra atividade importante são os reflorestamentos com Pinus sp para fornecimento de matéria prima às indústrias de celulose e seus derivados (EPAGRI, 1999).

A região serrana de Santa Catarina foi ocupada, inicialmente, por populações indígenas de língua Jê há mais de 2000 anos. A partir de 1730, a exploração de ouro em Minas Gerais gerou uma demanda de gado, cavalos e muares. Neste contexto, a região serrana catarinense se tornou área de passagem das tropas destes animais vindas do Rio

Revista Eletrônica: Tempo - Técnica - Território, V.5, N.1 (2014), 01:24 ISSN: 2177-4366 
Grande do Sul com destino a feira em Sorocaba (SP). Algumas tropas ficavam na região por longos períodos e alguns tropeiros permaneceram na região transformando-se em fazendeiros e criadores de gado. Em 1766, foi construído um povoado chamado a Vila de Nossa Senhora dos Prazeres das Lagens, atual cidade de Lages (PEIXER, 2002). A construção desta vila estava relacionada com a ocupação de posição estratégica de defesa do território colonial sul - brasileiro em relação aos espanhóis.

A ocupação desta região se caracterizou por espaços pouco delimitados, onde os trabalhadores das fazendas circulavam livremente, estabelecendo suas posses. Este processo estabeleceu uma hierarquia social composta por fazendeiros e suas famílias (proprietários de terra, dedicados a pecuária, com inúmeros agregados), os criadores (também proprietários, trabalhando com o auxílio da família e mais dois ou três peões), pequenos agricultores que plantavam utilizando-se do trabalho familiar, agregados que recebiam em espécie o pagamento pelo seu trabalho, e por peões assalariados, trabalhando na pecuária (BLOEMER, 2000). Esta estrutura sustentou a economia local até a década de 1940.

Também nesta região foram concedidas Sesmarias, com área equivalente a aproximadamente 10.800 ha. Diversas formas de posse informal da terra foram utilizadas pelos demais componentes da sociedade dos campos de Lages. A Lei de Terras de 1850 extinguiu as sesmarias e exigiu a demarcação das terras. Este evento dificultou o acesso a terra pela população pobre. Além disso, esta população pobre cresceu bastante com a vinda de famílias de outras regiões de conflitos sobre a terra (MUNARIM, 1990).

Abramovay (1992) apontou algumas constitutivas da sociedade da região serrana de Santa Catarina. Diferente de outras áreas do estado, não ocorreu a consolidação de próspera agricultura familiar por ser uma região de campos de passagem de rebanhos e de dependência personalizada entre peões e proprietários de terra. Além disso, são características locais a precariedade no acesso a terra, à informação, aos mercados e aos conhecimentos. Isto ajuda a explicar a grande pobreza da região.

Atualmente a área da região serrana catarinense é compreendida por um conjunto de onze municípios: Painel, Bocaina do Sul, Otacílio Costa, Palmeira, Correia Pinto, Lages, São José do Cerrito, Capão Alto, Campo Belo do Sul, Cerro Negro e Anita Garibaldi, conforme mostra a figura 1. Todos estes municípios foram criados a partir de desmembramentos do município de Lages. 

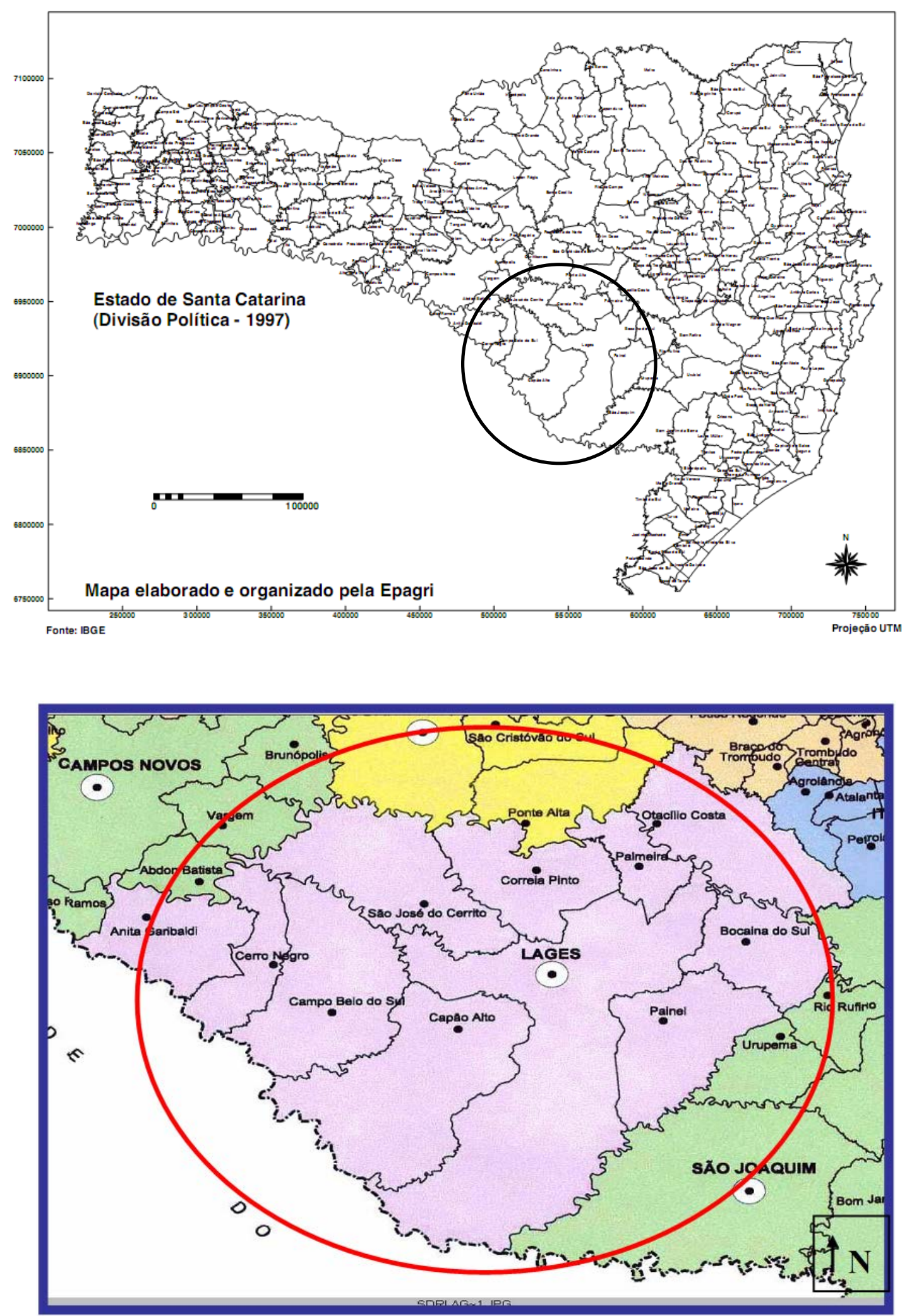

Fonte:Governo do Estado de Santa Catarina (2009)

Figura 1. Região do Planalto Serrano Catarinense 
Nesta região se desenvolveram alguns projetos de reordenamento em espaços rurais. Estes projetos utilizaram métodos diferentes para selecionar os participantes e adquirir as áreas a serem reordenadas. No entanto, todos têm em comum o objetivo central de possibilitar o acesso a terra para a população rural empobrecida. Um destes projetos está relacionado com a redistribuição de terras forçada por movimentos sociais. Outro projeto está vinculado ao reordenamento do espaço rural em função de uma grande obra de infraestrutura. O último projeto a ser analisado, diz respeito a utilização de um instrumento de reordenamento no espaço rural, o crédito fundiário.

\subsection{O processo de reordenamento no espaço rural através da redistribuição}

A atuação de movimentos sociais como MST, Via Campesina, Movimento das Mulheres Agricultoras entre outros forçou o reordenamento de áreas pela redistribuição em todo Brasil. Em Santa Catarina existem vários exemplos desta situação. No entanto, na região serrana catarinense o reordenamento baseado na desapropriação de áreas improdutivas e redistribuição para famílias sem terra não é um mecanismo muito utilizado (PEREIRA, 2009). Nesta região, existem apenas três (3) projetos deste tipo de reordenamento, o que corresponde a $3 \%$ do total realizado em Santa Catarina. O primeiro aconteceu no município de Ponte Alta em 2003. Foi desapropriada uma fazenda com área superior a 520 ha redistribuída para 45 famílias. O segundo projeto foi implantado no município de Correia Pinto em área maior que 1.160ha. A partir de 2006, foram assentados nesta área 70 famílias (INCRA, 2008).

No município de Campo Belo do Sul foi executado o projeto mais recente. Neste município, 2,5\% dos estabelecimentos estão acima de 500 ha, mas detêm 39\% da área total do município. Em janeiro de 2008, a Fazenda Santa Cruz com mais de 907 ha foi invadida por famílias do MST. Depois de estabelecer moradias na fazenda, foi formada uma comissão de trabalhadores que procuraram a prefeitura municipal e o INCRA solicitando a implantação eletricidade, educação para as crianças no acampamento e o estabelecimento do projeto de reordenamento da área por redistribuição. O objetivo foi redistribuir terras para 45 famílias provenientes de Lages, Otacílio Costa, Curitibanos e outras regiões do estado.

Em julho do mesmo ano a superintendência regional do INCRA em Santa Catarina foi imitida na posse da Fazenda Santa Cruz. Em seguida, foi publicada a portaria de criação do projeto de assentamento e a seleção dos beneficiários. Por fim, as

Revista Eletrônica: Tempo - Técnica - Território, V.5, N.1 (2014), 01:24 ISSN: 2177-4366 
famílias assinaram os contratos de assentamento e receberam os créditos de apoio inicial. Durante o primeiro ano, técnicos do INCRA e da Assistência Técnica, Social e Ambiental (ATES) elaboram o Plano de Desenvolvimento do Assentamento (PDA) para direcionar desenvolvimento economicamente sustentável da área (MDA, 2009).

\subsection{O processo de reordenamento no espaço rural em função de obras de engenharia para infraestrutura}

Desde a década de 1960, o governo federal brasileiro tem como política energética a construção de usinas hidrelétricas. Em todo território nacional diversas usinas foram contruídas a longo dos últimos 40 anos. Na região serrana de Santa Catarina também houve a contrução de uma usina, Barra Grande.

Boeira (2006) pesquisou o processo de reordenamento provocado pela construção desta obra de engenharia. O barramento foi construído no rio Pelotas a 43 km da confluência com o rio Canoas. A usina está compreendida entre os estados de Santa Catarina e Rio Grande do Sul. A área de influência direta e indireta compreendeu os municípios de Anita Garibaldi, Cerro Negro, Campo Belo do Sul, Capão Alto e Lages. Desde a autorização para realização de estudos de viabilidade, no ano de 19950 início do projeto, surgiram na região organizações da sociedade civil, como, sindicatos de trabalhadores, associações de pequenos produtores e movimentos sociais como MMA e MAB.

A análise do reordenamento em espaços rurais relacionado com a construção da usina hidrelétrica de Barra Grande revelou 3 processos importantes. O primeiro processo ocorreu entre o final da década de 1960 e o ano de 1995 . O conhecimento público dos projetos do setor elétrico para a região da bacia do rio Uruguai gerou uma mobilização significativa para a futura ação de alguns atores sociais. Nesta época surgiram grupos com diferentes interesses e formas de ação interessados no empreendimento: a) grupo da iniciativa privada, b) de instituições governamentais e político-administrativas, e em c) grupo de entidades não governamentais da sociedade civil organizada, ligadas diretamente aos interesses da população rural atingida pela UHE (BOEIRA, 2006). 
O segundo processo ocorreu entre os anos de 1995 e 2001. No início deste período foi outorgada a licença para realização de estudos de viabilidade técnica, econômica e ambiental do projeto UHE Barra Grande. Também nesta época foi divulgada a lista de famílias de agricultores fossem eles proprietários ou não, cujas áreas seriam afetadas pela construção da usina. Segundo o cadastramento realizado, o município de Anita Garibaldi concentrou cerca de 50\% do número total de famílias atingidas (184 famílias). Também foram atingidas familias dos municípios de Cerro Negro (109), Campo Belo do Sul (51), Capão Alto (42) e Lages (4 famílias). Assim, o reordenamento desta área incluiu trezentas e noventa (390) famílias (BOEIRA, 2006).

Com a divulgação deste cadastro ocorreram transformações físicas e simbólicas no espaço rural, como as primeiras desapropriações, a fragmentação de grupos sociais e a inserção de novos grupos, especialmente funcionários de empreiteiras e de empresas prestadoras de serviços (BOEIRA, 2006).

A partir de 1997, houve uma intensa atuação do grupo das instituições governamentais e político-administrativas, associadas à iniciativa privada, como também do grupo de entidades não governamentais ligadas aos interesses da população rural. As instituições governamentais e político-administrativas se mobilizaram para apoiar a construção da hidrelétrica. Foram realizadas três (3) audiências públicas e reuniões abertas denominadas Fóruns Pró UHE Barra Grande para divulgar informações sobre o empreendimento para a população (BOEIRA, 2006).

Por outro lado, as entidades não governamentais de apoio às comunidades rurais buscaram esclarecer os agricultores e trabalhadores rurais sobre seus direitos de posse e uso de suas terras. Além disso, buscaram fomentar a organização destes agricultores para as negociações sobre a venda e/ou indenização de suas propriedades e áreas de trabalho (BOEIRA, 2006).

O último processo apontado por Boeira (2006) teve início a partir do ano de 2001, com a liberação da Licença de Instalação (LI) e a concessão para exploração do potencial hidráulico do rio Pelotas. Neste período, foram realizadas ações concretas para a construção da hidrelétrica. O avanço das obras promoveu também o avanço das negociações para o reordenamento. A empresa construtora foi encarregada de comandar as negociações com os agricultores. Os agricultores entrevistados por Boeira (2006) sentiram-se lesados nas negociações que foram realizadas de forma individualizada.

Com isso os agricultores, organizados pelo MAB, passaram a pressionar a empresa através de ações judiciais. Uma das principais reivindicações era a explicitação 
dos critérios de avaliação dos imóveis contemplando além de valores econômicos também valores simbólicos. No final do ano de 2002, a empresa negociou com o MAB e formalizoualgumas diretrizes que viriam a ser a base para futuras operações. Estas diretrizes foram formalizadas no documento chamado Termo de Acordo para o Remanejamento da População Atingida pelo Aproveitamento Hidrelétrico Barra Grande. Entretanto, este acordo não foi cumprido gerando novas ações judiciais em 2003. Estas ações se estenderam até o final do ano de 2004. Neste ano uma negociação política, entre os Ministérios do Meio Ambiente, das Minas e Energia e a Casa Civil da Presidência da República, estabeleceu ações compensatórias concretas a serem executadas pela empresa tanto no que se refere ao reordenamento do espaço rural quanto aos danos ambientais decorrentes da formação do lago do reservatório. Novas ações judiciais foram empreendidas por organizações não governamentais visando o embargo da obra. O resultado destas ações foi a assinatura de Termo de Compromisso para a continuidade do processo de reordenamento respeitando parte das exigências dos agricultores (BOEIRA, 2008). Este processo se encerrou somente em 2008, quando foram publicadas as portarias do INCRA reconhecendo os projetos de assentamento de barragem relacionados à Barra Grande (INCRA, 2008).

\subsection{O processo de reordenamento no espaço rural utilizando o crédito fundiário}

No município de Cerro Negro nunca foram executados projetos de reordenamento agrário através da distribuição. Segundo dados do IBGE (2008), o município de Cerro Negro apresenta uma população de 4.053 habitantes e uma densidade demográfica de 9,46 habitantes/km². Embora a população seja predominante rural (83\% em 2000), está se intensificando a migração para outras regiões, processo iniciado a partir da década de 1970. O município apresenta uma renda per capita média, três vezes menor que a renda média de Santa Catarina. O número de pessoas pobres no espaço rural é de 73\%, e aproximadamente metade da população é considerada sem renda suficiente para garantir a sua própria alimentação. O Índice de Desenvolvimento Humano Municipal (IDH - M) é de 0,687, penúltimo lugar dentre os 293 municípios catarinenses.

Este município apresenta uma estrutura minifundiária de aproximadamente 90\%. Existem apenas sete (7) estabelecimentos com mais de 500 hectares que ocupam 27\% da área total. De um total de 994 das unidades de produção do município, 97\%, são geridas por agricultores familiares, dos quais $76 \%$ sobrevivem com menos de um salário

Revista Eletrônica: Tempo - Técnica - Território, V.5, N.1 (2014), 01:24 ISSN: 2177-4366 
mínimo por mês. Quanto a condição de propriedade da terra, a categoria dos proprietários detém 94,24 \% da área e 72,5\% dos estabelecimentos totais. O município apresenta agricultores familiares com baixo acesso a terra (arrendatários, parceiros e ocupantes).

A pesquisa de Pereira (2009) buscou analisar o processo de reordenamento em espaços rurais no município de Cerro Negro a partir da utilização de crédito fundiário. A iniciativa de utilizar este instrumento de reordenamento partiu dos interessados. Foram propostos 70 projetos de financiamento para compra de terrenos a partir do programa de crédito fundiário neste município. Destes, 30 projetos foram propostos por pequenos proprietários de terras e os outros 40 projetos foram inscritos por arrendatários e posseiros. Apenas dois projetos foram aprovados, um destes foi executado rapidamente e o outro esperou mais de 12 meses pela liberação dos recursos. Dos restantes, 28 projetos ainda estão em avaliação, todos inscritos por pequenos proprietários de terra. Os outros 40 projetos propostos por arrendatários e posseiros foram negados.

Para compreender o processo, foram entrevistadas 34 pessoas de três grupos sociais distintos de Cerro Negro. O primeiro grupo de informantes era composto por seis técnicos e lideranças de instituições locais (EPAGRI, Casa da Família Rural, Associações de Desenvolvimento de Microbacias e Sindicato de Trabalhadores Rurais) que compõem o Conselho Municipal de Desenvolvimento Rural, instância participativa responsável pelo planejamento estratégico da agricultura nos municípios brasileiros.

O segundo grupo de informantes era formado por 11 potenciais usuários do instrumento crédito fundiário. Entre os usuários potenciais estavam arrendatários, posseiros e indivíduos que possuem terras de herança com escrituras públicas não desmembradas em cinco comunidades rurais diferentes (Cruzeirinho, Beneditos, Umbú, Sagrado e Araçá). O terceiro conjunto de informantes foi composto por 17 membros de três associações comunitárias, a maioria filhos de pequenos proprietários de terras do município. Para todos os grupos foram feitas perguntas sobre processo de mobilização, acesso e operacionalização do crédito fundiário (PEREIRA, 2009).

Os resultados das entrevistas permitem perceber que não existe um processo de seleção de indivíduos para participarem de projetos de reordenamento no espaço rural a partir da concessão de crédito fundiário no município de Cerro Negro. Para que este instrumento seja utilizado, os próprios interessados devem conhecer o programa e estabelecer relações com o CMDR que valida os pedidos. Quanto aos critérios para

Revista Eletrônica: Tempo - Técnica - Território, V.5, N.1 (2014), 01:24 ISSN: 2177-4366 
participação no programa, a candidatura espontânea foi apontada como a melhor forma de seleção porque parte de pessoas com capacidade de iniciativa, capazes de compreender as normas do programa e que apresentam menor risco de não pagamento (PEREIRA, 2009).

Esta dinâmica favoreceu os pequenos proprietários de terras. Somente esta categoria de trabalhadores rurais teve seus projetos aprovados. Em geral, os proprietários têm nível de educação formal maior o que capacita para apresentar propostas e compreender as normas do programa. Além disso, estas pessoas têm maior articulação social com as lideranças de Cerro Negro presentes no CMDR; são capazes de comprovar a capacidade de pagamento (PEREIRA, 2009). Por outro lado, a dinâmica do processo de reordenamento em Cerro Negro a partir do crédito fundiário desfavoreceu os posseiros e arrendatários. Esta população tem baixo nível de educação formal e não estão envolvidas nas organizações sociais, sindicais e políticas que compõem o conselho decisório. Isto dificultou o acesso deste grupo ao programa, uma vez que tiveram dificuldades obter informações sobre o programa. Além disso, a falta de pessoal habilitado para a elaboração das propostas de financiamento no CMDR dificultou a participação desta parcela da população do município. Por fim, posseiros e arrendatários tiveram dificuldades em demonstrar capacidade de saldar o financiamento devido ao predomínio do trabalho informal. Nenhum projeto proposto por este grupo foi aprovado (PEREIRA, 2009).

\section{CONSIDERAÇÕES FINAIS}

Ao comparar os projetos de reordenamento em espaços rurais ocorridos na região serrana de Santa Catarina é possível destacar algumas características. Todos os projetos buscaram atender, principalmente, ao objetivo de possibilitar o acesso a terra para todos. A exceção do projeto relacionado à construção da hidrelétrica, nos demais projetos não contemplaram o aperfeiçoamento da infraestrutura para população e para produção agrícola, não melhoraram a produção primária, e não buscaram evitar o crescimento desordenado das ocupações humanas. Assim, é possível afirmar que estes objetivos não estão presentes na fase de elaboração dos projetos. A explicação para este fato pode estar na falta de profissionais habilitados elaborando tais projetos (HONG; NEEDHAM, 2007). Como foi descrito, em muitos projetos a população interessada no 
reordenamento foi responsável pela elaboração dos projetos. O poder público apenas avaliou, aprovando ou descartando tais projetos.

Quando o reordenamento em espaços rurais é conduzido desta forma existem grandes chances de não existir viabilidade para sua execução. É possível que estes projetos descritos tenham se preocupado apenas com a viabilidade econômica, uma vez que as famílias de agricultores necessitavam conhecer as atividades econômicas desenvolvidas na região para poder inserir suas produções no mercado com condições de comercialização. No entanto, no que se refere a viabilidade ecológica apenas as áreas reordenadas pelo INCRA recebem assistência técnica e fiscalização freqüente relacionada com o cumprimento da legislação ambiental brasileira. As demais áreas são fiscalizadas pelo órgão estadual de meio ambiente que possui deficiências de pessoal e infraestrutura para tal. Já no que se refere à viabilidade social, o acesso a terra é considerado essencial enquanto aspectos como paisagem, usos coletivos e culturas são, muitas vezes, tratados como secundários. Sparovek (2003) aponta que nos processos de reordena mento redistributivo as políticas governamentais privilegiam a aquisição de áreas e o assentamento de famílias e realizam poucos investimentos em ações que contribuem para melhorar a condição de vida e a produção econômica dos projetos.

Segundo Hong e Needham (2007) existem duas alternativas viáveis para o reordenamento territorial: a troca voluntária ou a intervenção pública na forma de expropriação. Em Santa Catarina é possível perceber variações destas alternativas. O crédito fundiário combina ação estatal através do estabelecimento da política pública de financiamento e a ação voluntária dos interessados. Esta estratégia de reordenamento pode ser uma alternativa interessante para grupos que não tem vinculação com os movimentos sociais que promovem o reordenamento redistributivo. Sua aplicação permitiria o acesso a terra de filhos de agricultores com pequenas propriedades, cuja herança seria insuficiente para a produção agrícola.

O reordenamento relacionado à construção de obras de engenharia associa a intervenção estatal que obriga os empreendedores a negociar o deslocamento das populações atingidas e a participação da comunidade de agricultores organizados que negociam as condições do deslocamento. Por fim, o reordenamento através de desapropriações e parcelamentos de grandes propriedades improdutivas também combina a ação governamental através de legislação específica e da ação do órgão responsável pela reforma agrária, com a ação social das famílias de agricultores sem terra. 
Assim, na área de estudo a intervenção estatal não foi o motor dos processos de reordenamento. De fato é papel do Estado no Brasil garantir a vida, a segurança. Muitas destes objetivos podem ser atingidos através do reordenamento territorial. No entanto, a principal dificuldade para reordenar é como reunir direitos de propriedade privados.

A análise dos projetos de reordenamento em espaços rurais ocorridos na região serrana de Santa Catarina pode trazer contribuições para a discussão sobre aplicações do reordenamento em situações complexas que requerem soluções mais eficientes e justas do que aquelas possibilitadas pelos instrumentos hoje existentes.

\section{REFERÊNCIAS}

ABRAMOVAY, R. Paradigmas do capitalismo agrário em questão. São Paulo: Hucitec, 1992.

BOEIRA, S.M. Estudo da Dinâmica Territorial Rural: a implantação da usina hidrelétrica Barra Grande no planalto sul catarinense. 103f. Dissertação (Mestrado em Agroecossistemas) - Centro de Ciências Agrárias, Universidade Federal de Santa Catarina. Florianópolis, 2006

BLOEMER, N.M.C. Brava Gente Brasileira: migrantes italianos e caboclos nos Campos de Lages. Florianópolis: Cidade Futura, 2000.

BRANDÃO, W. A reforma agrária solidária do Ceará. Brasília: Ministério do Desenvolvimento Agrário. Reforma Agrária e Desenvolvimento Sustentável, 2000.

CAMARGO, L. O Banco da Terra em Santa Catarina: da crítica às possibilidades. Dissertação (Mestrado em Agroecossistemas). Centro de Ciências Agrárias, Universidade Federal de Santa Catarina. Florianópolis, 2003

CAZELLA, A.A. Trajetória de desenvolvimento e caracterização socioeconômica da região serrana de Santa Catarina. Relatório de Projeto de Pesquisa, 2006.

CONDÉ, P.A.A. Acesso a terra e a visão do público não mobilizado em acampamentos: o crédito fundiário do município de Caçador - SC. Dissertação (Mestrado em Agroecossistemas). Centro de Ciências Agrárias, Universidade Federal de Santa Catarina. Florianópolis, 2006.

EPAGRI/CIRAM. Empresa de Pesquisa Agropecuária e Extensão Rural de Santa Catarina. Zoneamento Agroecológico e Socioeconômico. Florianópolis: Epagri, 1999.

FERREIRA, C. L; ANJOS, R. S. S. O território dos maracatus-nação de pernambuco: interpretação preliminar. Revista Tempo, técnica e território. v. 3, n. 1, p. 46-80, 2012. 
HONG, Y.H.; NEEDHAM, B. Analyzing Land Readjustment: Economics, Law and Collective Action. Cambridge, MA: Lincoln Institute of Land Policy, 2007.

IBGE. Instituto Brasileiro de Geografia e Estatística. Censo 2006. Disponível em www.ibge.gov.br. Acessado em 12 dez 2009.

IBGE. Instituto Brasileiro de Geografia e Estatística. Mapa de Santa Catarina. Disponível em www.ibge.gov.br. Acessado em 12 dez 2009.

INCRA. Instituto de Colonização e Reforma Agrária. Assentamentos em Santa Catarina em 2008. Disponível em www.ibge.gov.br. Acessado em 12 dez 2009.

LEITE, S.P.; ÁVILA, R.V. Um futuro para o campo: reforma agrária e desenvolvimento social. Rio de Janeiro: Vieira \& Lent, 2007.

LOCH, C.; ERBA, D.A. Cadastro Técnico Multifinalitário: rural e urbano. Cambridge, MA: Lincoln Institute of Land Policy, 2007. 142p.

MDA. Ministério do Desenvolvimento Agrário. Assentamentos da reforma agrária em Santa Catarina. Disponível em www.mda.gov.br. Acessado em 12 dez 2009.

MARIGHELLA, E.T. A questão agrária: textos dos anos sessenta. São Paulo: Editora Brasil Debates, 1980.

MEDEIROS, L.S. História dos movimentos sociais no campo. Rio de Janeiro: Fase, 2002.

MUNARIM, A. Educação e esfera pública na serra catarinense: a experiência política do Plano Regional de Educação. Florianópolis: EdUfsc, 2000.

NEUMANN, P.S. O impacto da fragmentação e do formato das terras nos sistemas familiares de produção. Florianópolis, 2003. Tese (Doutorado em Engenharia de Produção). Programa de Pós-Graduação em Engenharia de Produção da Universidade Federal de Santa Catarina.

PEREIRA, S.A. O crédito fundiário como mecanismo de acesso à terra: estudo de caso no município de Cerro Negro- Santa Catarina. 137p. Dissertação (Mestrado em Agroecossistemas) - Centro de Ciências Agrárias, Universidade Federal de Santa Catarina. Florianópolis, 2006

PEREIRA, J.M.M. O modelo de reforma agrária de mercado do Banco Mundial em questão: o debate internacional e o caso brasileiro. Teoria, luta política e balanços de resultados. Mestrado (Programa de Pós-Graduação em Desenvolvimento, Agricultura e Sociedade). Centro de Pesquisa e Desenvolvimento da Agricultura, Universidade Federal Rural do Rio de Janeiro, 2004.

PEIXER, Z.I. A cidade e seus tempos: O processo de constituição do espaço urbano em Lages. Lages: Editora UNIPLAC, 2002. 
SANTA CATARINA. Governo do Estado. Mapa da região serrana de Santa Catarina. Disponível em www.sc.gov.br. Acessado em 12 dez 2009.

SEYFERTH, Giralda. Identidade nacional, diferenças regionais, integração étnica e a questão migratória no Brasil. In: Região e Nação na América Latina (ZARUR, J. C. L., ed.). Brasília: Editora da UNB: São Paulo: Imprensa Oficial do Estado, 2000, p. 81 109 